\title{
Article \\ Complementary Metaresonator Sensor with Dual Notch Resonance for Evaluation of Vegetable Oils in C and $X$ Bands
}

\author{
Ammar Armghan \\ Department of Electrical Engineering, College of Engineering, Jouf University, Skaka 72388, Saudi Arabia; \\ aarmghan@ju.edu.sa; Tel.: +966-146-544444
}

check for updates

Citation: Armghan, A.

Complementary Metaresonator

Sensor with Dual Notch Resonance for Evaluation of Vegetable Oils in C and X Bands. Appl. Sci. 2021, 11, 5734. https://doi.org/10.3390/ app11125734

Academic Editor: Benjamin Potelon

Received: 17 May 2021

Accepted: 17 June 2021

Published: 21 June 2021

Publisher's Note: MDPI stays neutral with regard to jurisdictional claims in published maps and institutional affiliations.

Copyright: (c) 2021 by the authors. Licensee MDPI, Basel, Switzerland. This article is an open access article distributed under the terms and conditions of the Creative Commons Attribution (CC BY) license (https:// creativecommons.org/licenses/by/ $4.0 /)$.

\begin{abstract}
This paper investigates the effect of complementary metaresonator for evaluation of vegetable oils in $\mathrm{C}$ and $\mathrm{X}$ bands. Tremendously increasing technology demands the exploration of complementary metaresonators for high performance in the related bands. This research probes the complementary mirror-symmetric $S$ resonator (CMSSR) that can operate in two bands with compact size and high sensitivity features. The prime motivation behind the proposed technique is to utilize the dual notch resonance to estimate the dielectric constant of the oil under test (OUT). The proposed sensor is designed on a compact $30 \times 25 \mathrm{~mm}^{2}$ and $1.6 \mathrm{~mm}$ thick FR-4 substrate. A $50 \Omega$ microstrip transmission line is printed on one side, while a unit cell of CMSSR is etched on the other side of the substrate to achieve dual notch resonance. A Teflon container is attached to CMSSR in the ground plane to act as a pool for the OUT. According to the simulated transmission spectrum, the proposed design manifested dual notch resonance precisely at $7.21 \mathrm{GHz}(\mathrm{C}$ band) and $8.97 \mathrm{GHz}$ (X band). A prototype of complementary metaresonator sensor is fabricated and tested using CEYEAR AV3672D vector network analyzer. The comparison of measured and simulated data shows that the difference between the first resonance frequency is $0.01 \mathrm{GHz}$ and the second is $0.04 \mathrm{GHz}$. Furthermore, a mathematical model is developed for the complementary metaresonator sensor to evaluate dielectric constant of the OUT in terms of the relevant, resonant frequency.
\end{abstract}

Keywords: complementary mirror-symmetric $S$ resonator; dielectric constant; dual notch; metaresonator sensor; oil under test

\section{Introduction}

Complementary metaresonator-based microwave sensors have high sensitivity, fast response time, broad sensing range, inexpensive fabrication, and high accuracy and are appropriate for diverse climates; therefore, these sensors are very popular in research and industrial applications. These sensors can be employed for the identification of electromagnetic properties of gases [1,2], liquids [3,4], and solids [5,6] in various frequency bands. Metamaterials were theoretically predicted by V. G. Veselago in 1968 [7] and experimentally verified by D. R. Smith in 2000 [8]. The main components of metamaterials are split-ring resonators (SRRs) [9] and complementary split-ring resonators (CSRRs) [10]. Recently, the development of theoretical and experimental models within the scope of microwave sensing using SRR and CSRR has led to the potential applications for biomedical [11,12], chemical $[13,14]$, and electronic sector $[15,16]$.

SRR was a superconducting resonator [17] before its introduction as a microstructure with imaginary magnetic permeability components. Initially, it was used to demonstrate left-handed behavior [18], negative refraction [19], backward wave radiation [20], negative group velocity [21], stopband [22], and passband filters [23]. Later on it was used to design alignment sensor [24], biosensor [25], displacement sensor [26], microfluidic sensor [27], rotation sensor [28], strain sensor [29], thin-film sensor [30], and velocity sensor [31]. SRR based sensors have a very narrow region for the electric field concentration between the splits at the resonance, which interacts with the material under test (MUT). These 
sensors are not suitable for testing large samples due to the small sensing area; CSRR solves this problem. By applying the babinet principle on SSR [32], its dual counterpart was introduced as CSRR. Initially, CSRR was used to design metamaterial transmission lines [33], passband [34] and stopband filters [35]. Later on, it was used to measure dielectric loss tangent [36], liquid characterization [37], thickness measurement [38], and evaluation of permittivity [39].

In the recent past, several techniques have been proposed to calculate the dielectric properties of oil samples [40-43]. In [40], a single port sensor based on CSRR is presented to detect adulteration of edible oils with a minimum frequency shift of $14 \mathrm{MHz}$ in the $\mathrm{X}$ band. An analytical method is proposed in [41] to calculate the dielectric constant and loss tangent of oils based on a CSRR sensor with a resonant frequency of $2.5 \mathrm{GHz}$ and an average sensitivity of $3.58 \%$. In [42], a metamaterial sensor operating at millimeter-wave is designed to evaluate the oils and their chemical characteristics with a frequency shift of $1.12 \mathrm{GHz}$. A submersible single-port microwave sensor is presented in [43] to evaluate the complex permittivity of oils based on multiple complementary SRR with a resonant frequency of $8.49 \mathrm{GHz}$ and an average sensitivity $7.25 \%$. However, the aforementioned sensors have sensitivity limitations due to noncompact structure design and minor interaction of electromagnetic fields with the OUT. Furthermore, most of the proposed sensors for oil testing are based on single resonance frequency, which causes low precision and less accuracy in measurement.

This paper proposes a dual notch metaresonator sensor with high sensitivity, compact size, low cost, and convenient operation. The proposed complementary mirror-symmetric $\mathrm{S}$ resonator (CMSSR) shows dual notch resonance in the $\mathrm{C}$ and $\mathrm{X}$ bands. The CMSSR is coupled electrically with the microstrip transmission line for excitation, and a Teflon container is attached to the CMSSR, which makes it suitable for oil characterization. The unique design of the proposed metaresonator sensor and simulation analysis is explained in Section 2. Measurement setup and characterization of oil samples are accomplished in Section 3. Mathematical modeling of the measured data is performed in Section 4. Finally, the main results and technical contributions are summarized in Section 5.

\section{Design of Metaresonator Sensor}

The design of the proposed sensor is straightforward with five different layers, as shown in Figure 1. The first layer consists of $0.035 \mathrm{~mm}$ thick copper in a $3 \mathrm{~mm}$ microstrip transmission line (MTL) configuration. The second layer comprises a $1.6 \mathrm{~mm}$ FR-4 substrate with the dimensions $30 \mathrm{~mm} \times 25 \mathrm{~mm}$. The relative permittivity $\left(\epsilon_{r}\right)$ and dielectric loss tangent $(\tan \delta)$ of FR- 4 substrate are 4.4 and 0.02 , respectively. The effective dielectric constant $\left(\epsilon_{r e}\right)$ of MTL is 3.326 , and characteristic impedance $\left(Z_{c}\right)$ is $50 \Omega$. These parameters $\left(\epsilon_{r e}\right.$ and $\left.Z_{c}\right)$ are calculated using the following equations [44]:

$$
\epsilon_{r e}=\frac{\epsilon_{r}+1}{2}+\frac{\epsilon_{r}-1}{2}\left(1+\frac{10}{u}\right)^{-a b}
$$

where $u=w / h, a=1+\frac{1}{49} \ln \left(\frac{u^{4}+\left(\frac{u}{52}\right)^{2}}{u^{4}+0.432}\right)+\frac{1}{18.7} \ln \left[1+\left(\frac{u}{18.1}\right)^{3}\right]$, and $b=0.564\left(\frac{\epsilon_{r}-0.9}{\epsilon_{r}+3}\right)^{0.053}$.

$$
Z_{c}=\frac{\eta}{2 \pi \sqrt{\epsilon_{r e}}} \ln \left[\frac{F}{u}+\sqrt{1+\left(\frac{2}{u}\right)^{2}}\right],
$$

where $u=w / h, \eta=120 \pi \Omega$, and $F=6+(2 \pi-6) \exp \left[-\left(\frac{30.666}{u}\right)^{0.7528}\right]$.

Complementary mirror-symmetric $\mathrm{S}$ resonator (CMSSR) is etched in the third layer known as the ground plane. The fourth layer consists of $0.01 \mathrm{~mm}$ thick polyimide doublesided adhesive film, which is used to connect the third and fifth layers. The fifth layer consists of a $1 \mathrm{~mm}$ thick Teflon container that will act as a pool for OUT. 


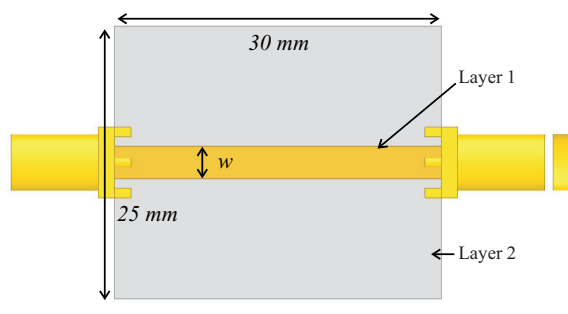

(a) Top View

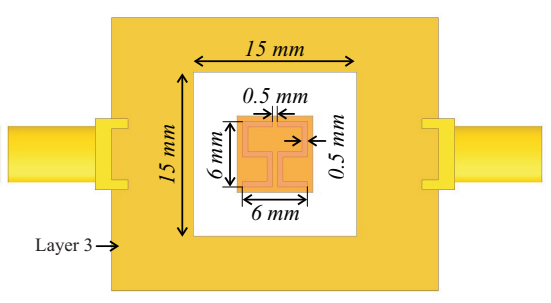

(b) Bottom View

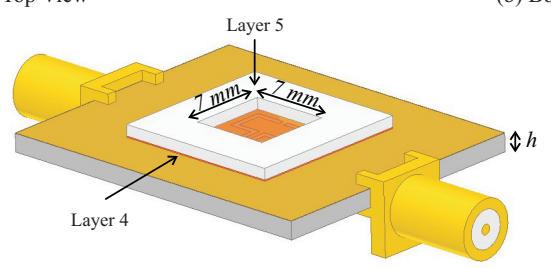

(c) Dimetric View

Figure 1. Three dimensional view of complementary metaresonator sensor. (a) Top view of the sensor where $w=3 \mathrm{~mm}$, (b) Bottom view of the sensor, (c) Dimetric view of the sensor where $h=1.6 \mathrm{~mm}$.

The size of the CMSSR resonator is $6 \mathrm{~mm} \times 6 \mathrm{~mm}$, and the width of resonator lines is $0.5 \mathrm{~mm}$. The effect of geometrical dimensions on the bandwidth and unloaded $Q$ factor is already discussed in Reference [45]. According to [45], the maximum value of the $Q$ factor is achieved using a $0.5 \mathrm{~mm}$ wide resonator. The substrate and pool material are selected due to low cost, and the thickness is chosen due to easy availability. The proposed metaresonator sensor is simulated in ANSYS Electronics Suite 2021 with the conditions given in Table 1. The magnitude and phase of transmission $\left(S_{21}\right)$ and reflection $\left(S_{11}\right)$ coefficients for the metaresonator sensor are shown in Figure 2 and Figure 3, respectively. The simulated transmission spectrum shows that the metaresonator sensor provides dual notch resonance with wide bandwidth. The first and second notch has a resonance at $7.21 \mathrm{GHz}$ with a notch depth of $-23.85 \mathrm{~dB}$, and $8.97 \mathrm{GHz}$ with a notch depth of $-21.57 \mathrm{~dB}$, respectively. The unloaded quality $(Q)$ factor of first notch is 55.38 , and that of the second notch is 21.26 . The unloaded $(Q)$ factor of the metaresonator sensor is measured by the $S_{21}$ using the following equation [46]:

$$
Q=\frac{f_{r}}{\Delta f_{3 d B}} .
$$

Table 1. Simulation conditions for ANSYS Electromagnetics Suite 2020R1.

\begin{tabular}{lll}
\hline \multirow{2}{*}{ Analysis Area } & $\begin{array}{l}\text { Size } \\
\text { Boundary Condition }\end{array}$ & $\begin{array}{l}25 \times 30 \times 1.6 \mathrm{~mm}^{3} \\
\text { Radiation }\end{array}$ \\
\hline \multirow{2}{*}{ Cells } & $\begin{array}{l}\text { Number } \\
\text { Shape }\end{array}$ & $\begin{array}{l}14,201 \\
\text { Tetrahedron }\end{array}$ \\
\hline Feed & & Wave port $(50 \Omega)$ \\
\hline Solution Type & Driven Model \\
\hline Frequency Sweep & $0.1 \mathrm{GHz}$ to $30 \mathrm{GHz}$ \\
\hline \multirow{2}{*}{ Convergence condition determination } & Maximum number of passes; 20 \\
& Maximum delta S; 0.02 \\
\hline
\end{tabular}




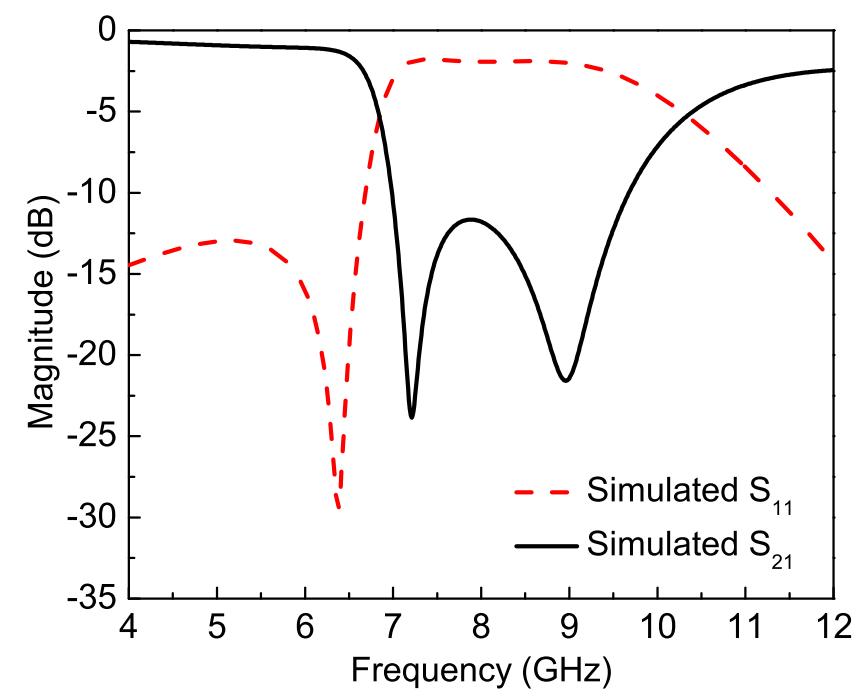

Figure 2. The magnitude of transmission $\left(S_{21}\right)$ and reflection $\left(S_{11}\right)$ coefficients for the metaresonator sensor. The first and second notches have a resonance at $7.21 \mathrm{GHz}$ with notch depth $-23.85 \mathrm{~dB}$ and 8.97 GHz with notch depth $-21.57 \mathrm{~dB}$.

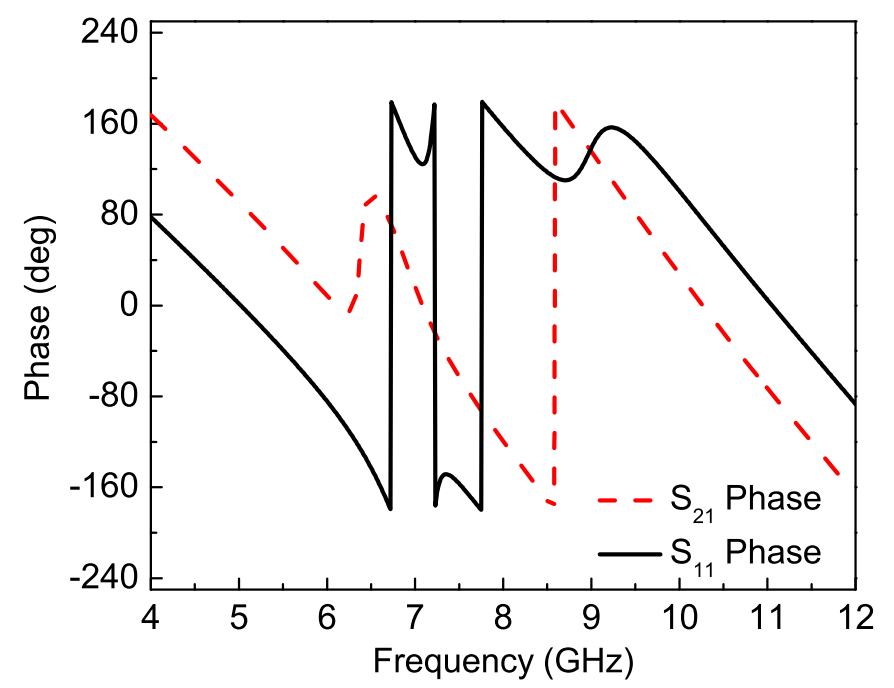

Figure 3. The phase of transmission $\left(S_{21}\right)$ and reflection $\left(S_{11}\right)$ coefficients for the metaresonator sensor. Near resonance frequencies, there is sudden change in phase.

\section{Measurement Setup}

For experimental verification, the proposed complementary metaresonator sensor was fabricated using standard PCB fabrication technique and measured on CEYEAR AV3672D series vector network analyzer (VNA), as shown in Figure 4. The VNA is calibrated with a frequency sweep of $4 \mathrm{GHz}$ to $12 \mathrm{GHz}$ and a step size of $0.01 \mathrm{GHz}$. The fabricated prototype of the complementary metaresonator sensor is connected to VNA using SMA connectors, and $S_{21}$ is measured. The measured resonance frequency of the first notch is $7.20 \mathrm{GHz}$ and the second notch is $8.93 \mathrm{GHz}$, as shown in Figure 5. The percentage errors between the measured and simulated results for the first and second notch are $0.13 \%$ and $0.44 \%$, respectively. Figure 6 shows the measurement environment for oil characterization, and a single adjustable channel automatic pipette (Dragon Lab, 10-100 $\mu \mathrm{L}$ ) is used to measure the quantity of oils. The quantity of each OUT is chosen $40 \mu \mathrm{L}$ to fill the Teflon container, and measurements are performed at room temperature. Measurements are taken very 
carefully to characterize the oils with dielectric constant ranges from 2.52 to 4.47 . The dielectric and chemical properties of common available vegetable oils are given in Table 2. Figure 7 shows the complementary metaresonator sensor loaded with the OUT. In order to reduce the contamination of the previous OUT, the sensor is cleaned with alcohol using a cotton ball. Before the subsequent measurement, it ensures that the alcohol is evaporated and the resonance frequency of the unloaded sensor is returned to its original state. Four samples of vegetable oils are used to measure the $S_{21}$ of the sensor as shown in Figure 8, and results are listed in Table 3. The effect of the dielectric constant of the OUT on the resonance frequencies of the complementary metaresonator sensor is shown in Figure 9.

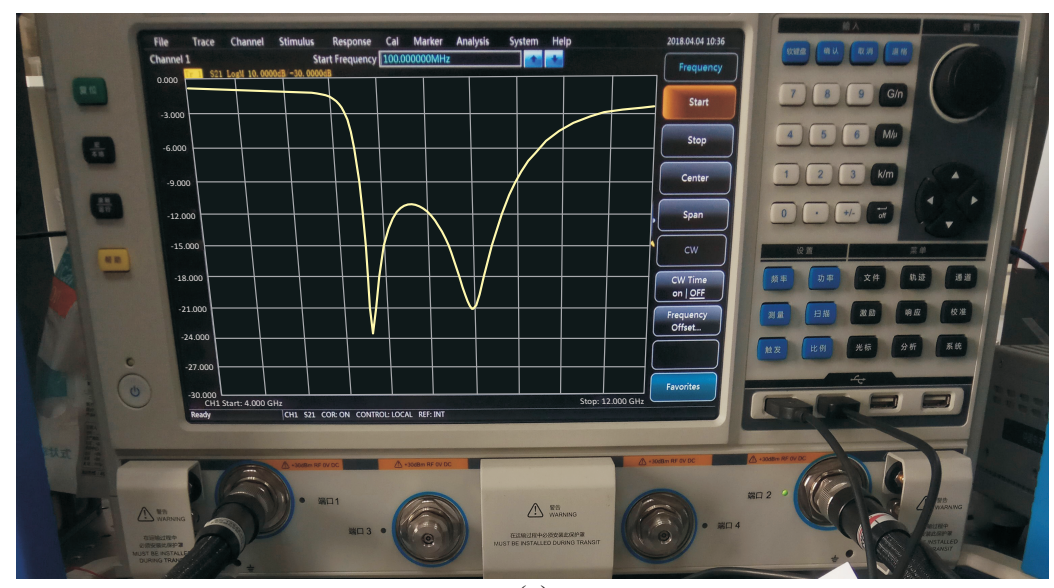

(a)

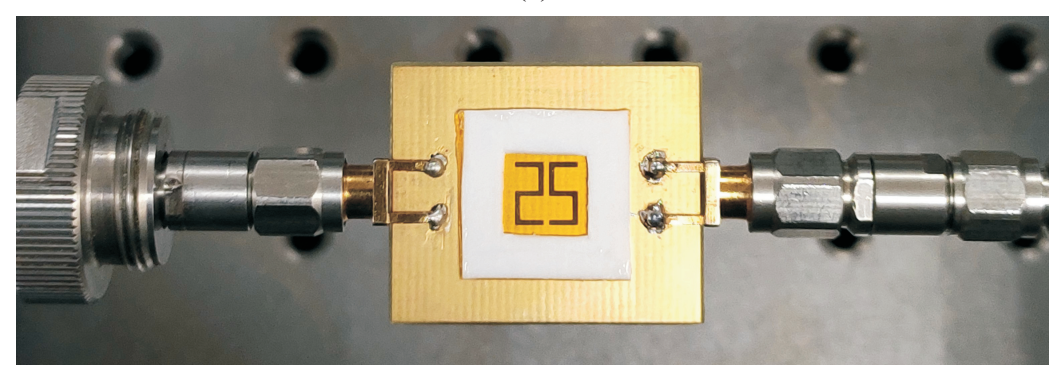

(b)

Figure 4. (a) Photograph of CEYEAR AV3672D series vector network for measurement, (b) fabricated prototype of the complementary metaresonator sensor.

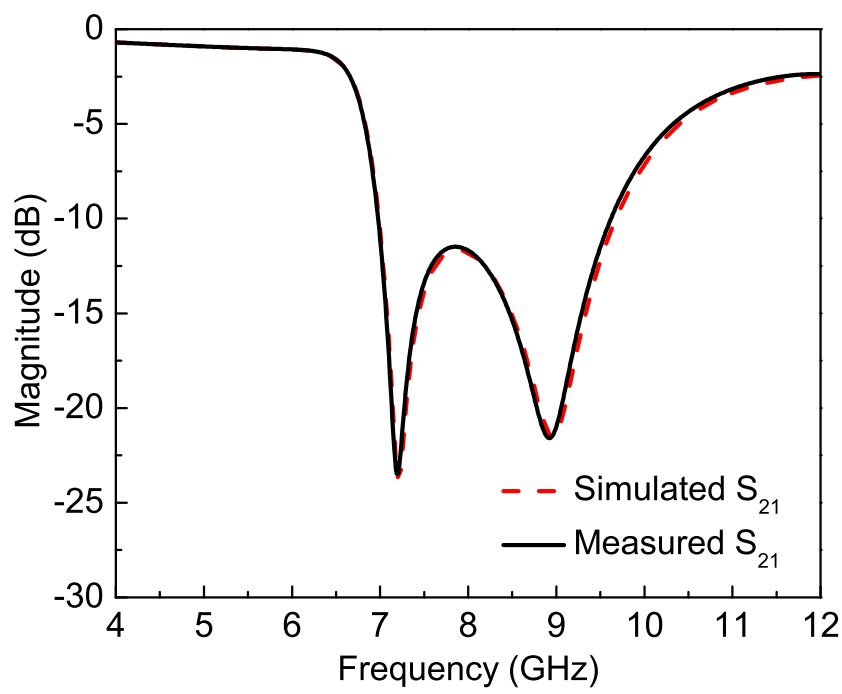

Figure 5. The magnitude of transmission $\left(S_{21}\right)$ coefficient for simulated and measured metaresonator sensor. The unloaded $Q$ factor of the first notch is 55.38 and that of the second notch is 21.26. 
Table 2. Dielectric and chemical properties of OUT [42,47].

\begin{tabular}{cccccc}
\hline Name & $\begin{array}{c}\text { Chemical } \\
\text { Name }\end{array}$ & $\begin{array}{c}\text { Molecular } \\
\text { Formula }\end{array}$ & $\begin{array}{c}\text { Iodine Contents } \\
\text { (gI } / \mathbf{1 0 0} \text { g) }\end{array}$ & $\begin{array}{c}\text { Dielectric } \\
\text { Constant }\end{array}$ & $\begin{array}{c}\text { Dielectric } \\
\text { Loss Tangent }\end{array}$ \\
\hline Corn Oil & - & - & 110 & 2.526 & 0.0566 \\
Coconut Oil & Trilaurin & $\mathrm{C}_{3} \mathrm{H}_{5}\left(\mathrm{C}_{12} \mathrm{H}_{23} \mathrm{O}_{2}\right)_{3}$ & - & 2.83 & - \\
Olive Oil & Triolein & $\mathrm{C}_{3} \mathrm{H}_{5}\left(\mathrm{C}_{18} \mathrm{H}_{33} \mathrm{O}_{2}\right)_{3}$ & 84 & 3.352 & 0.0331 \\
Castor Oil & Triricinolein & $\mathrm{C}_{3} \mathrm{H}_{5}\left(\mathrm{C}_{18} \mathrm{H}_{33} \mathrm{O}_{3}\right)_{3}$ & 85 & 4.47 & 0.0322 \\
\hline
\end{tabular}

Table 3. Measured $S_{21}$ for the complementary metaresonator sensor due to interaction with different OUT.

\begin{tabular}{cccccc}
\hline $\begin{array}{c}\text { Oil Under } \\
\text { Test (OUT) }\end{array}$ & $\begin{array}{c}\text { Dielectric } \\
\text { Constant }\end{array}$ & $\begin{array}{c}\text { Measured } \\
\text { First Resonance } \\
\text { Frequency (GHz) }\end{array}$ & $\begin{array}{c}\text { Notch } \\
\text { Depth (dB) }\end{array}$ & $\begin{array}{c}\text { Measured } \\
\text { Second Resonance } \\
\text { Frequency (GHz) }\end{array}$ & $\begin{array}{c}\text { Notch } \\
\text { Depth (dB) }\end{array}$ \\
\hline Air & 1.0006 & 7.20 & -23.51 & 8.93 & -21.57 \\
Corn Oil & 2.526 & 6.72 & -18.71 & 8.22 & -20.21 \\
Coconut Oil & 2.83 & 6.64 & -18.39 & 8.12 & -2.91 \\
Olive Oil & 3.352 & 6.50 & -19.28 & 7.56 & -21.06 \\
Castor Oil & 4.47 & 6.26 & -18.43 & -14 \\
\hline
\end{tabular}



(a)

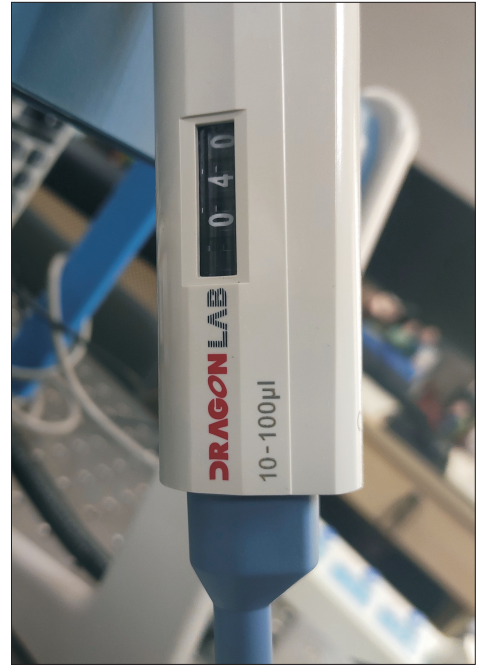

(b)

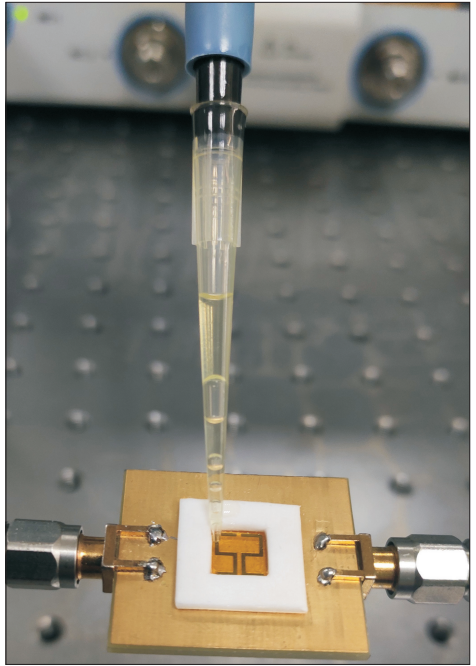

(c)

Figure 6. Measurement environment (a) dragon lab 10-100 $\mu \mathrm{L}$ adjustable single channel automatic pipette, (b) oil quantity measurement, (c) pouring the OUT into the Teflon container. 


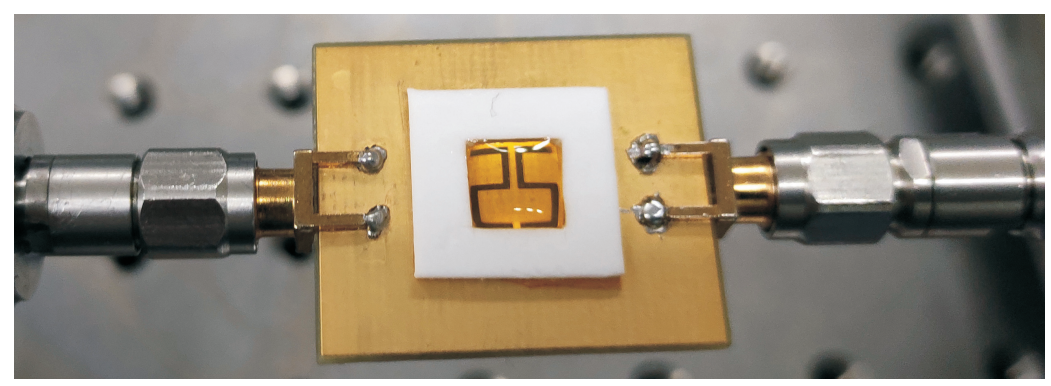

Figure 7. Complementary metaresonator sensor loaded with the OUT.



Figure 8. The magnitude of transmission $\left(S_{21}\right)$ coefficients for the complementary metaresonator sensor due to interaction with different OUT.



Figure 9. Dielectric constant of OUT versus the resonance frequency of the sensor due to interaction with the OUTs. 
In Figure 9, the slopes of the first (red curve), and second (blue curve) curves provide the fabricated metaresonator sensor's sensitivity, which can be measured mathematically using the following relation [48]:

$$
S=\frac{\partial f_{d}}{\partial \epsilon_{r d}}=\lim _{\left(\Delta \epsilon_{r 2}-\Delta \epsilon_{r 1}\right) \rightarrow 0} \frac{\Delta f_{u}-\Delta f_{l}}{\Delta \epsilon_{r 2}-\Delta \epsilon_{r 1}} .
$$

Using (4), the sensitivity of the complementary metaresonator sensor is calculated and tabulated in Table 4. The sensitivity of second resonance is higher than the first resonance due to the higher resonance frequency for all the OUTs. The sensitivity of corn oil is maximum due to small dielectric constant. The sensitivity due to the first resonance frequency lies between $31.4 \%$ to $27 \%$ and that due to the second resonance is between $46.5 \%$ and $39.4 \%$.

Table 4. Relative sensitivity of the complementary metaresonator sensor with respect to OUT.

\begin{tabular}{|c|c|c|c|}
\hline Oil Under Test (OUT) & Dielectric Constant & Sensitivity of First Resonance (\%) & Sensitivity of Second Resonance (\%) \\
\hline Corn Oil & 2.526 & 31.4 & 46.5 \\
\hline Coconut Oil & 2.83 & 30.6 & 44.2 \\
\hline Olive Oil & 3.352 & 29.7 & 43.3 \\
\hline Castor Oil & 4.47 & 27 & 39.4 \\
\hline
\end{tabular}

\section{Mathematical Modeling for Oil Characterization}

The mathematical model for the measured data is obtained using the curve fitting technique. To achieve the best fitting curve, the technique of least squares is used. According to this technique, the sum of deviation must be minimum for a best fitting curve [49]:

$$
\sum_{1}^{n} e_{i}^{2}=\sum_{1}^{n}\left[y_{i}-f\left(x_{i}\right)\right]^{2},
$$

where $e_{i}$ is the deviation, $x$ is the independent variable and $y$ is the dependent variable. The least error $(E)$ for the best fitting polynomial $y=a_{1}+a_{2} x+a_{3} x^{2}$ is:

$$
E=\sum_{1}^{n} e_{i}^{2}=\sum_{1}^{n}\left[y_{i}-\left(a_{1}+a_{2} x_{i}+a_{3} x_{i}^{2}\right)\right]^{2},
$$

For $E$ to be minimum, the following conditions are compulsory: $\frac{\partial E}{\partial a}=0, \frac{\partial E}{\partial b}=0$, and $\frac{\partial E}{\partial c}=0$. By applying these conditions to Equation (6), the unknown coefficients $\left(a_{1}, a_{2}\right.$, and $a_{3}$ ) for the best fitted polynomial are calculated in the form of the following matrix:

$$
\left[\begin{array}{l}
a_{1} \\
a_{2} \\
a_{3}
\end{array}\right]=\left[\begin{array}{ccc}
n & \sum x_{i} & \sum x_{i}^{2} \\
\sum x_{i} & \sum x_{i}^{2} & \sum x_{i}^{3} \\
\sum x_{i}^{2} & \sum x_{i}^{3} & \sum x_{i}^{4}
\end{array}\right]^{-1}\left[\begin{array}{c}
\sum y_{i} \\
\sum x_{i} y_{i} \\
\sum x_{i}^{2} y_{i}
\end{array}\right],
$$

The best fitting polynomial for the complementary metaresonator sensor can be expressed as:

$$
f_{i}=a_{1}+a_{2} \epsilon_{r}+a_{3} \epsilon_{r}^{2}
$$

where $f_{i}$ is the dependent variable and $\epsilon_{r}$ is the independent variable. For the first and second resonance of the fabricated complementary metaresonator sensor, the unknown coefficients $\left(a_{1}, a_{2}\right.$, and $\left.a_{3}\right)$ are calculated using matrix (7), and the results given in Table 3. The equations for $f_{1}$ and $f_{2}$ are given as:

$$
\begin{aligned}
& f_{1}=7.362-0.221 \epsilon_{r}-0.007 \epsilon_{r}^{2}, \\
& f_{2}=9.234-1.079 \epsilon_{r}-0.0005 \epsilon_{r}^{2} .
\end{aligned}
$$


Equations (9) and (10) are used to calculated to the resonance frequencies of the complementary metaresonator sensor due to interaction with the OUT and tabulated in Table 5. The measured and formulated results are very close to each other. The complementary metaresonator sensor is compared for sensitivity and application with others available sensors in the literature. The sensitivity of proposed complementary metaresonator sensor is high as compared to other state-of-the-art sensors, as tabulated in Table 6.

Table 5. Comparison of measured and formulated resonance frequencies of the proposed complementary metaresonator sensor.

\begin{tabular}{cccccc}
\hline $\begin{array}{c}\text { Oil Under } \\
\text { Test (OUT) }\end{array}$ & $\begin{array}{c}\text { Dielectric } \\
\text { Constant }\end{array}$ & $\begin{array}{c}\text { Measured } \\
f_{\mathbf{1}}(\mathbf{G H z})\end{array}$ & $\begin{array}{c}\text { Formulated } \\
\boldsymbol{f}_{\mathbf{1}} \mathbf{( G H z )}\end{array}$ & $\begin{array}{c}\text { Measured } \\
f_{\mathbf{2}}(\mathbf{G H z})\end{array}$ & $\begin{array}{c}\text { Formulated } \\
\boldsymbol{f}_{\mathbf{2}} \mathbf{( G H z )}\end{array}$ \\
\hline Air & 1.0006 & 7.20 & 7.13 & 8.93 & 8.85 \\
Corn Oil & 2.526 & 6.72 & 6.75 & 8.22 & 8.26 \\
Coconut Oil & 2.83 & 6.64 & 6.67 & 8.12 & 8.15 \\
Olive Oil & 3.352 & 6.50 & 6.53 & 7.91 & 7.94 \\
Castor Oil & 4.47 & 6.26 & 6.22 & 7.56 & 7.51 \\
\hline
\end{tabular}

Table 6. Comparison of the proposed complementary metaresonator sensor with various state of art sensors.

\begin{tabular}{|c|c|c|c|c|c|}
\hline References & $\begin{array}{l}\text { Sensor } \\
\text { Design }\end{array}$ & $\begin{array}{l}\text { Method } \\
\text { of Sensing }\end{array}$ & $\begin{array}{c}\text { Operating } \\
\text { Frequency }(\mathrm{GHz})\end{array}$ & Sensitivity (GHz) & Applications \\
\hline [41] & CSRR & Transmission Coefficient S21 & 2.52 & 0.08 & Oil Characterization \\
\hline [50] & SIW & Reflection Coefficient S11 & 16 & 0.14 & Chemical \\
\hline [51] & CSRR & Transmission Coefficient $S$ & 2.3 & 0.1 & Water-Ethanol Mixtures \\
\hline [52] & ECRs & Electric Coupling Coefficient ke & - & - & Dielectric Materials \\
\hline [53] & OLSIR & Electric Coupling & 4.40 & - & Glucose Concentration \\
\hline [54] & OLMR & Unloaded Q factor & 1.92 & 0.46 & Glucose Concentration \\
\hline [55] & PSRR & Transmission Coefficient S21 & 1.9 & 0.2 & Bacterial Growth \\
\hline [56] & Omega & Transmission Coefficient S21 & 2 & 0.05 & Methanol \\
\hline [57] & M-CRR & Transmission Coefficient S21 & 2.4 & 0.06 & Liquids \\
\hline [58] & PMWR & Transmission Coefficient S21 & 1.5 & 0.01 & Liquids \\
\hline [59] & SRRs & Transmission Coefficient S21 & 0.87 & 0.07 & Liquids \\
\hline [60] & SIRs & Transmission Coefficient S21 & 3 & 0.05 & Dielectric Materials \\
\hline [61] & CSRRs & Transmission Coefficient S21 & 1.7 & 0.03 & Substrates \\
\hline Proposed & CMSSR & Transmission Coefficient S21 & 7.20 & 0.48 & Vegetable Oils \\
\hline
\end{tabular}

\section{Conclusions}

In this work, a dual notch complementary metaresonator sensor is designed, simulated, fabricated, and measured to evaluate vegetable oils. Furthermore, a mathematical model for the proposed sensor is obtained using the least square curve-fitting technique, and a good agreement is achieved between measured and formulated results. The complementary metaresonator sensor is based on five layers: one FR-4, one polyimide, one Teflon, and two copper layers. A complementary mirror-symmetric $S$ resonator (CMSSR) unit is used as a metaresonator with some unique features like dual notch resonance, strong electromagnetic field concentration, and high sensitivity. The sensitivity of the first notch is $31.4 \%$, and that of the second notch is $46.5 \%$, of the complementary metaresonator sensor due to interaction with the corn oil. The normalized average sensitivity of the proposed metaresonator sensor is high compared to that of the other microwave sensors. Due to its unique design, broad sensing range, and high sensitivity, evaluating the vegetable oils with a very close dielectric constant is possible. The simple and inexpensive fabrication makes the proposed sensor very attractive for the oil industry.

Author Contributions: A.A. designed, simulated, fabricated, and measured the proposed complementary metaresonator sensor with technical help from INZA Research Laboratory for Electromagnetic Field and Microwave Engineering. All authors have read and agreed to the published version of the manuscript.

Funding: The author extends his appreciation to the Deanship of Scientific Research at Jouf University for funding this work through research grant No 466/39. 
Conflicts of Interest: The author declare no conflict of interest.

\section{References}

1. Li, F.; Zheng, Y.; Hua, C.; Jian, J. Gas sensing by microwave transduction: Review of progress and challenges. Front. Mater. 2019, 6, 101. [CrossRef]

2. $\quad$ Park, J.K.; Kang, T.G.; Kim, B.H.; Lee, H.J.; Choi, H.H.; Yook, J.G. Real-time Humidity Sensor Based on Microwave Resonator Coupled with PEDOT:PSS Conducting Polymer Film. Sci. Rep. 2018, 8, 439. [CrossRef] [PubMed]

3. Zhang, X.; Ruan, C.; Haq, T.; Chen, K. High-Sensitivity Microwave Sensor for Liquid Characterization Using a Complementary Circular Spiral Resonator. Sensors 2019, 19,787. [CrossRef] [PubMed]

4. Zhang, K.; Amineh, R.K.; Dong, Z.; Nadler, D. Microwave Sensing of Water Quality. IEEE Access 2019, 7, 69481-69493. [CrossRef]

5. Haq, T.; Ruan, C.; Zhang, X.; Ullah, S.; Fahad, A.K. Complementary Metamaterial based Dual Notch Microwave Sensor. In Proceedings of the 2020 International Conference on Microwave and Millimeter Wave Technology (ICMMT), Shanghai, China, 20-23 September 2020.

6. Haq, T.; Ruan, C.; Zhang, X.; Ullah, S.; Fahad, A.K. Microwave Sensor Based on Complementary Spiral Resonator with Fitting Equation to Evaluate Dielectric Substrates. In Proceedings of the 2019 International Conference on Microwave and Millimeter Wave Technology (ICMMT), Guangzhou, China, 19-22 May 2019.

7. Veselago, V.G. The electrodynamics of substances with simultaneously negative values of $\epsilon$ and $\mu$. Sov. Phys. Uspekhi 1968, 10, 509-514. [CrossRef]

8. Smith, D.R.; Padilla, W.J.; Vier, D.C.; Nemat-Nasser, S.C.; Schultz, S. Composite medium with simultaneously negative permeability and permittivity. Phys. Rev. Lett. 2000, 84, 4184-4187. [CrossRef]

9. Falcone, F.; Lopetegi, T.; Baena, J. Effective Negative- $\epsilon$ Stopband Microstrip Lines Based on Complementary Split Ring Resonators. IEEE Microw. Wirel. Components Lett. 2004, 14, 280-282. [CrossRef]

10. Pendry, J.B.; Holden, A.J.; Robbins, D.J.; Stewart, W.J. Magnetism from conductors and enhanced nonlinear phenomena. IEEE Trans. Microw. Theory Tech. 1999, 47, 2075-2084. [CrossRef]

11. Omer, A.E.; Shaker, G.; Safavi-Naeini, S.; Kokabi, H.; Alquié, G.; Deshours, F.; Shubair, R.M. Low-cost portable microwave sensor for non-invasive monitoring of blood glucose level: Novel design utilizing a four-cell CSRR hexagonal configuration. Sci. Rep. 2020, 10, 15200. [CrossRef]

12. Zarifi, M.H.; Sadabadi, H.; Hejazi, S.H.; Daneshmand, M.; Sanati-Nezhad, A. Noncontact and Nonintrusive MicrowaveMicrofluidic Flow Sensor for Energy and Biomedical Engineering. Sci. Rep. 2018, 8, 139. [CrossRef]

13. Ebrahimi, A.; Tovar-Lopez, F.J.; Scott, J.; Ghorbani, K. Differential microwave sensor for characterization of glycerol-water solutions. Sens. Actuators B Chem. 2020, 321, 1-8. [CrossRef]

14. Javed, A.; Arif, A.; Zubair, M.; Mehmood, M.Q.; Riaz, K. A Low-Cost Multiple Complementary Split-Ring Resonator-Based Microwave Sensor for Contactless Dielectric Characterization of Liquids. IEEE Sens. J. 2020, 20, 11326-11334. [CrossRef]

15. Haq, T.; Ruan, C.; Zhang, X.; Ullah, S. Complementary Metamaterial Sensor for Nondestructive Evaluation of Dielectric Substrates. Sensors 2019, 19, 2100. [CrossRef] [PubMed]

16. Fan, L.C.; Zhao, W.S.; Gan, H.Y.; He, L.; Liu, Q.; Dong, L.; Wang, G. A high-Q active substrate integrated waveguide based sensor for fully characterizing magneto-dielectric (MD) materials. Sens. Actuators A Phys. 2020, 301, 111778. [CrossRef]

17. Delayen, J.R.; Dick, G.J.; Mercereau, J.E. Test of A $\beta \simeq 0.1$ superconducting split ring resonator. IEEE Trans. Magn. 1981, 17, 939-942. [CrossRef]

18. Marqués, R.; Martel, J.; Mesa, F.; Medina, F. Left-Handed-Media Simulation and Transmission of EM Waves in Subwavelength Split-Ring-Resonator-Loaded Metallic Waveguides. Phys. Rev. Lett. 2002, 89, 5-8. [CrossRef] [PubMed]

19. Eleftheriades, G.V.; Iyer, A.K.; Kremer, P.C. Planar negative refractive index media using periodically L-C loaded transmission lines. IEEE Trans. Microw. Theory Tech. 2002, 50, 2702-2712. [CrossRef]

20. Grbic, A.; Eleftheriades, G.V. Experimental verification of backward-wave radiation from a negative refractive index metamaterial. J. Appl. Phys. 2002, 92, 5930-5935. [CrossRef]

21. Siddiqui, O.F.; Mojahedi, M.; Eleftheriades, G.V. Periodically Loaded Transmission Line with Effective Negative Refractive Index and Negative Group Velocity. IEEE Trans. Antennas Propag. 2003, 51, 2619-2625. [CrossRef]

22. Martín, F.; Falcone, F.; Bonache, J.; Marqués, R.; Sorolla, M. Miniaturized Coplanar Waveguide Stop Band Filters Based on Multiple Tuned Split Ring Resonators. IEEE Microw. Wirel. Components Lett. 2003, 13, 511-513. [CrossRef]

23. Falcone, F.; Martín, F.; Bonache, J.; Marqués, R.; Lopetegi, T.; Sorolla, M. Left Handed Coplanar Waveguide Band Pass Filters Based on Bi-layer Split Ring Resonators. IEEE Microw. Wirel. Components Lett. 2004, 14, 10-12. [CrossRef]

24. Naqui, J.; Durán-Sindreu, M.; Martín, F. Alignment and position sensors based on split ring resonators. Sensors 2012, 12, 11790-11797. [CrossRef]

25. Lee, H.J.; Lee, H.S.; Yoo, K.H.; Yook, J.G. DNA sensing using split-ring resonator alone at microwave regime. J. Appl. Phys. 2010, 108, 1-6. [CrossRef]

26. Mata-Contreras, J.; Herrojo, C.; Martin, F. Application of Split Ring Resonator (SRR) Loaded Transmission Lines to the Design of Angular Displacement and Velocity Sensors for Space Applications. IEEE Trans. Microw. Theory Tech. 2017, 65, 4450-4460. [CrossRef] 
27. Wiltshire, B.D.; Rafi, M.A.; Zarifi, M.H. Microwave resonator array with liquid metal selection for narrow band material sensing. Sci. Rep. 2021, 11, 8598. [CrossRef]

28. Ebrahimi, A.; Withayachumnankul, W.; Al-Sarawi, S.F.; Abbott, D. Metamaterial-inspired rotation sensor with wide dynamic range. IEEE Sens. J. 2014, 14, 2609-2614. [CrossRef]

29. Thai, T.T.; Aubert, H.; Pons, P.; Dejean, G.; Mtentzeris, M.; Plana, R. Novel design of a highly sensitive RF strain transducer for passive and remote sensing in two dimensions. IEEE Trans. Microw. Theory Tech. 2013, 61, 1385-1396. [CrossRef]

30. Galindo-Romera, G.; Javier Herraiz-Martínez, F.; Gil, M.; Martínez-Martínez, J.J.; Segovia-Vargas, D. Submersible Printed Split-Ring Resonator-Based Sensor for Thin-Film Detection and Permittivity Characterization. IEEE Sens. J. 2016, 16, 3587-3596. [CrossRef]

31. Herrojo, C.; Mata-Contreras, J.; Paredes, F.; Martín, F. Microwave Encoders for Chipless RFID and Angular Velocity Sensors Based on S-Shaped Split Ring Resonators. Appl. Phys. Lett. 2017, 17, 4805-4813. [CrossRef]

32. Falcone, F.; Lopetegi, T.; Laso, M.A.G.; Baena, J.D.; Bonache, J.; Beruete, M.; Marques, R.; Martín, F.; Sorolla, M. Babinet principle applied to the design of metasurfaces and metamaterials. Phys. Rev. Lett. 2004, 93, 2-5. [CrossRef] [PubMed]

33. Bonache, J.; Gil, M.; Gil, I.; García-garcía, J.; Martín, F. On the Electrical Characteristics of Complementary Metamaterial Resonators. IEEE Microw. Wirel. Components Lett. 2006, 16, 543-545. [CrossRef]

34. Haq, T.; Khan, M.F.; Siddiqui, O.F. Design and implementation of waveguide bandpass filter using complementary metaresonator. Appl. Phys. A Mater. Sci. Process. 2016, 122, 1-5. [CrossRef]

35. Haq, T.; Ruan, C.; Ullah, S.; Kosar, A. Reconfigurable Ultra Wide Band Notch Filter based on Complementary Metamaterial. In Proceedings of the IEEE Asia-Pacific Conference on Antennas and Propagation, Auckland, New Zealand, 5-8 August 2018; pp. 381-382.

36. Lee, C.S.; Yang, C.L. Complementary split-ring resonators for measuring dielectric constants and loss tangents. IEEE Microw. Wirel. Components Lett. 2014, 24, 563-565. [CrossRef]

37. Ebrahimi, A.; Scott, J.; Ghorbani, K. Ultrahigh-Sensitivity Microwave Sensor for Microfluidic Complex Permittivity Measurement. IEEE Trans. Microw. Theory Tech. 2019, 67, 4269-4277. [CrossRef]

38. Yang, C.; Lee, C.; Chen, K.; Chen, K. Noncontact Measurement of Complex Permittivity and Thickness by Using Planar Resonators. IEEE Trans. Microw. Theory Tech. 2016, 64, 247-257. [CrossRef]

39. Haq, T.; Ruan, C.; Zhang, X.; Ullah, S.; Fahad, A.K.; He, W. Extremely sensitive microwave sensor for evaluation of dielectric characteristics of low-permittivity materials. Sensors 2020, 20, 1916. [CrossRef]

40. Tiwari, N.K.; Singh, S.P.; Akhtar, M.J. Novel Improved Sensitivity Planar Microwave Probe for Adulteration Detection in Edible Oils. IEEE Microw. Wirel. Components Lett. 2019, 29, 164-166. [CrossRef]

41. Su, L.; Mata-Contreras, J.; Vélez, P.; Fernández-Prieto, A.; Martín, F. Analytical method to estimate the complex permittivity of oil samples. Sensors 2018, 18, 984. [CrossRef]

42. Qureshi, S.A.; Abidin, Z.Z.; Ashyap, A.Y.I.; Majid, H.A.; Kamarudin, M.R.; Yue, M.; Zulkipli, M.S.; Nebhen, J. Millimetre-Wave Metamaterial-Based Sensor for Characterisation of Cooking Oils. Int. J. Antennas Propag. 2021, 1, 1-10. [CrossRef]

43. Zhang, X.; Ruan, C.; Wang, W.; Cao, Y. Submersible High Sensitivity Microwave Sensor for Edible Oil Detection and Quality Analysis. IEEE Sens. J. 2021, 1, 1-9.

44. Hong, J.-S. Microstrip Filters for RF/Microwave Applications; Wiley and Sons: New York, NY, USA, 2011; ISBN 9780470408773.

45. Haq, T.; Ruan, C.; Zhang, X.; Kosar, A.; Ullah, S. Low cost and compact wideband microwave notch filter based on miniaturized complementary metaresonator. Appl. Phys. A Mater. Sci. Process. 2019, 125, 1-7. [CrossRef]

46. Arif Hussain Ansari, M.; Jha, A.K.; Akhter, Z.; Jaleel Akhtar, M. Multi-Band RF Planar Sensor Using Complementary Split Ring Resonator for Testing of Dielectric Materials. IEEE Sens. J. 2018, 18, 6596-6606. [CrossRef]

47. Mohamad, N.A.; Azis, N.; Jasni, J.; Ab Kadir, M.Z.A.; Yunus, R.; Ishak, M.T.; Yaakub, Z. A study on the dielectric properties of Palm Oil and Coconut Oil. In Proceedings of the 2014 IEEE International Conference on Power and Energy (PECon), Kuching, Malaysia, 1-3 December 2014.

48. Haq, T.; Ruan, C.; Ullah, S.; Kosar Fahad, A. Dual Notch Microwave Sensors Based on Complementary Metamaterial Resonators. IEEE Access 2019, 7, 153489-153498. [CrossRef]

49. Armghan, A.; Alanaz, T.M.; Altaf, A.; Haq, T. Characterization of Dielectric Substrates Using Dual Band Microwave Sensor. IEEE Access 2021, 9, 62779-62787. [CrossRef]

50. Memon, M.U.; Lim, S. Millimeter-wave chemical sensor using substrate-integrated-waveguide cavity. Appl. Sens. 2016, 16, 1829. [CrossRef]

51. Chuma, E.L.; Iano, Y.; Fontgalland, G.; Bravo Roger, L.L. Microwave sensor for liquid dielectric characterization based on metamaterial complementary split ring resonator. IEEE Sens. J. 2018, 18, 9978-9983. [CrossRef]

52. Herrera-Sepulveda, L.V.; Olvera-Cervantes, J.L.; Corona-Chavez, A.; Kaur, T. Sensor and methodology for determining dielectric constant using electrically coupled resonators. IEEE Microw. Wirel. Components Lett. 2019, 29, 626-628. [CrossRef]

53. Juan, C.G.; Potelon, B.; Quendo, C.; Bronchalo, E.; Sabater-Navarro, J.M. Highly-Sensitive Glucose Concentration Sensor Exploiting Inter-resonators Couplings. In Proceedings of the 49th European Microwave ConferenceAt, Paris, France, 1-3 Octoner 2019; pp. 662-665. 
54. Juan, C.G.; Bronchalo, E.; Potelon, B.; Quendo, C.; Ávila-Navarro, E.; Sabater-Navarro, J.M. Concentration Measurement of Microliter-Volume Water-Glucose Solutions Using Q Factor of Microwave Sensors. IEEE Trans. Instrum. Meas. 2019, 68, 2621-2634. [CrossRef]

55. Mohammadi, S.; Nadaraja, A.V.; Luckasavitch, K.; Jain, M.C.; June Roberts, D.; Zarifi, M.H. A Label-Free, Non-Intrusive, and Rapid Monitoring of Bacterial Growth on Solid Medium Using Microwave Biosensor. IEEE Trans. Biomed. Circuits Syst. 2020, 14, 2-11. [CrossRef]

56. Abdulkarim, Y.I.; Deng, L.; Karaaslan, M.; Altıntaş, O.; Awl, H.N.; Muhammadsharif, F.F.; Liao, C.; Unal, E.; Luo, H. Novel metamaterials-based hypersensitized liquid sensor integrating omega-shaped resonator with microstrip transmission line. Sensors 2020, 20, 943. [CrossRef]

57. Ebrahimi, A.; Scott, J.; Ghorbani, K. Microwave reflective biosensor for glucose level detection in aqueous solutions. Sens. Actuators A Phys. 2020, 301, 1-8. [CrossRef]

58. Zarifi, M.H.; Daneshmand, M. Liquid sensing in aquatic environment using high quality planar microwave resonator. Sens. Actuators B Chem. 2016, 225, 517-521. [CrossRef]

59. Velez, P.; Su, L.; Grenier, K.; Mata-Contreras, J.; Dubuc, D.; Martin, F. Microwave Microfluidic Sensor Based on a Microstrip Splitter/Combiner Configuration and Split Ring Resonators (SRRs) for Dielectric Characterization of Liquids. IEEE Sens. J. 2017, 17, 6589-6598. [CrossRef]

60. Su, L.; Mata-Contreras, J.; Vélez, P.; Martín, F. Configurations of splitter/combiner microstrip sections loaded with stepped impedance resonators (SIRs) for sensing applications. Sensors 2016, 16, 2195. [CrossRef]

61. Su, L.; Mata-Contreras, J.; Vélez, P.; Martín, F. Splitter/Combiner Microstrip Sections Loaded With Pairs of Complementary Split Ring Resonators Differential Sensing Applications. IEEE Trans. Microw. Theory Tech. 2016, 64, 4362-4370. [CrossRef] 